\title{
Araucária (Paraná, Brasil): um território para o turismo industrial
}

\author{
Araucária (Paraná, Brazil): a territory for the tourism industry
}

\author{
Neide de Moura (MOURA, N.)
}

\begin{abstract}
RESUMO - Este artigo tem por finalidade discutir a potencialidade para possíveis formatações de produtos turísticos na modalidade de turismo industrial, no Município de Araucária (Paraná, Brasil). Para tanto, se fez uso do conceito de território imbuído de consonantes geográficos que nortearam a proposta, que, por sua vez, buscará nos estudos sobre territorialidade (HAESBAERT, 2009) um enfoque das possíveis organizações de territórios para o turismo no referido município, bem como a organização de territorialidades e multiterritorialidades por parte dos turistas que a visitem. Como resultado verificou-se a existência de condições para o desenvolvimento de programações e visitações aos empreendimentos industriais do município.
\end{abstract}

Palavras-chave: Território; Territorialidade; Multiterritorialidades; Turismo industrial.

ABSTRACT - This article aims to discuss the potentialities for tourism products possible formats in the industrial tourism modality in Araucária (Paraná, Brazil). For that, it was used the territory concept impregnated of geographical consonants that guided the proposal, which will seek in studies of territoriality (HAESBAERT, 2009) a focus of possible territory organizations for tourism in the referred city, as well as the territoriality and multi-territoriality organization by tourists who visit it. As a result, it was found the existence of conditions to develop programs and visitations to the industrial enterprises in the city.

Key words: Territory; Territoriality; Multi-territoriality; Industrial Tourism.

\footnotetext{
* Bacharel e licenciada em Geografia pela Universidade Federal do Paraná (UFPR). Mestre e doutoranda em Geografia (UFPR). Professora formadora no Município de Araucária - Paraná (PR). Endereço para correspondência: Rua Tadeu Milan, 104 (Bloco 14, apartamento 204). CEP: 83708-060 - Araucária Paraná (PR/Brasil). E-mail: neidedemoura@gmail.com
}

Turismo \& Sociedade, Curitiba, v. 3, n. 2, p. 220-235, outubro de 2010 


\section{INTRODUÇÃO}

Vive-se um momento no qual os territórios perdem um pouco de seu sentido enquanto estados-nações com fronteiras bem delimitadas e quase intransponíveis. As marcas deixadas pelo viés da globalização nas últimas décadas encurtam distâncias e aproximam territórios agindo como fator preponderante para a diminuição da energia frenética de controle territorial estabelecida nas fronteiras.

Neste sentido, as viagens são cada vez mais possíveis e viáveis entre distâncias cada vez maiores, inexistindo a impossibilidade quase que total em se visitar este ou aquele local devido a não possibilidade em se chegar até ele. Com isso, os territórios ganham uma conotação diferenciada. Pode-se entrar e sair deles e não estabelecer vínculos duradouros. Ou então, estabelecer vínculos diferenciados e diversificados, que se estreitam ou se perdem dependendo da influência que sofram durante seus processos de organização. A estes tipos de vínculos se nomeiam de territorialidades, ou ainda de multiterritorialidades (HAESBAERT, 2009), caso haja o fortalecimento dos vínculos.

Como exemplo, pode-se citar os casos em que comunidades receptoras adéquam seus hábitos de vida para melhor atender à demanda de visitantes, mudando parte de sua cultura.

No âmbito do turismo estes tipos de vínculos podem se concretizar ou não. Tudo irá depender da duração da estadia e da empatia estabelecida entre o turista e o lugar visitado, vinculando-se ao tempo de permanência e da afeição do mesmo com o lugar. Estes vínculos ou territorialidades serão dispostos no decorrer do texto para melhor se compreender a discussão que se pretende abordar com a colocação do Município de Araucária localizado no Estado do Paraná (PR), Brasil, como um território para o turismo industrial.

A elaboração do presente artigo constou de pesquisas bibliográficas e da utilização de fontes eletrônicas que tratam sobre o assunto. Uma das bases conceituais utilizadas foi o conceito de território e de territorialidade ou multiterritorialidades retratados no trabalho de Haesbaert (2009), comentados no decorrer do texto.

A organização textual do artigo foi realizada com a divisão do mesmo em quatro partes, dentre as quais se encontram a introdução e a conclusão. Na parte teórica tem-se uma contextualização sobre o município, o panorama da atividade turística e da sua 
infraestrutura. A parte restante trata de uma abordagem sobre as indústrias instaladas em seu território, bem como de indagações sobre o turismo industrial encarado como possibilidade ou complemento para a atividade turística já existente sob as formas de turismo rural e de negócios.

Sendo deste modo, julga-se pertinente realizar em primeiro momento um ordenamento do pensamento em relação ao Município e seu histórico com a atividade turística.

\section{O MUNICÍPIO DE ARAUCÁRIA E A ATIVIDADE TURÍSTICA}

A compreensão do que seria o trato mantido pelo Município de Araucária com a atividade turística requer que se avaliem inicialmente suas características mais singulares em relação ao seu desenvolvimento econômico e cultural. Então, se procura, preliminarmente, evidenciar o panorama geral em que se insere o Município.

\subsection{CONTEXTUALIZAÇÃO DO MUNICÍPIO}

O município de Araucária se situa na Região Metropolitana de Curitiba (RMC), no Primeiro Planalto Paranaense, ocupando uma área de $460,85 \mathrm{~km}^{2}$, na altitude de 857 m acima do nível do mar (ARAUCÁRIA, 1999). Vide figura 1. O desenvolvimento econômico do Município se deu com maior ênfase durante a década de 1970, assim, como também o foi em todo o Estado do Paraná, devido à vinda de indústrias, sobretudo as do complexo metal-mecânico concentradas em Curitiba (MOURA, 2009). Tal fato gerou um surto de desenvolvimento ao setor industrial que possui características diferenciadas e inovadoras em relação aos movimentos anteriores que tinha características de inserções locais. Segundo Firkowski (2001, p. 25) tal diferenciação se deve ao foco de tais empreendimentos uma vez que estes se originaram no sentido de atender a outros mercados (nacionais e internacionais), com controle acionário externo, esvaindo-se da estrutura local que possuíam outrora.

A evolução econômica do Município se deu em três fases (ARAUCÁRIA, 1999). A primeira no início do século $X X$, estimulada pelo consumo interno do Município. Eram olarias, serrarias, cervejarias, engenhos de mate e fábricas de barricas, Turismo \& Sociedade, Curitiba, v. 3, n. 2, p. 220-235, outubro de 2010 
utilizadas para o transporte do mate beneficiado. A segunda fase se constitui pela produção de tecido de linho, pela fábrica São Manoel, filial em Araucária da matriz de São Paulo, a São Patrício. A terceira e grande fase se deu com a implantação da Refinaria Presidente Getúlio Vargas (REPAR) em 1972 pela estatal Petróleo Brasileiro S. A. (PETROBRÁS), fato que provocou a organização e implementação do Centro Industrial de Araucária (CIAR) em 1973, ocasionando rápida industrialização.

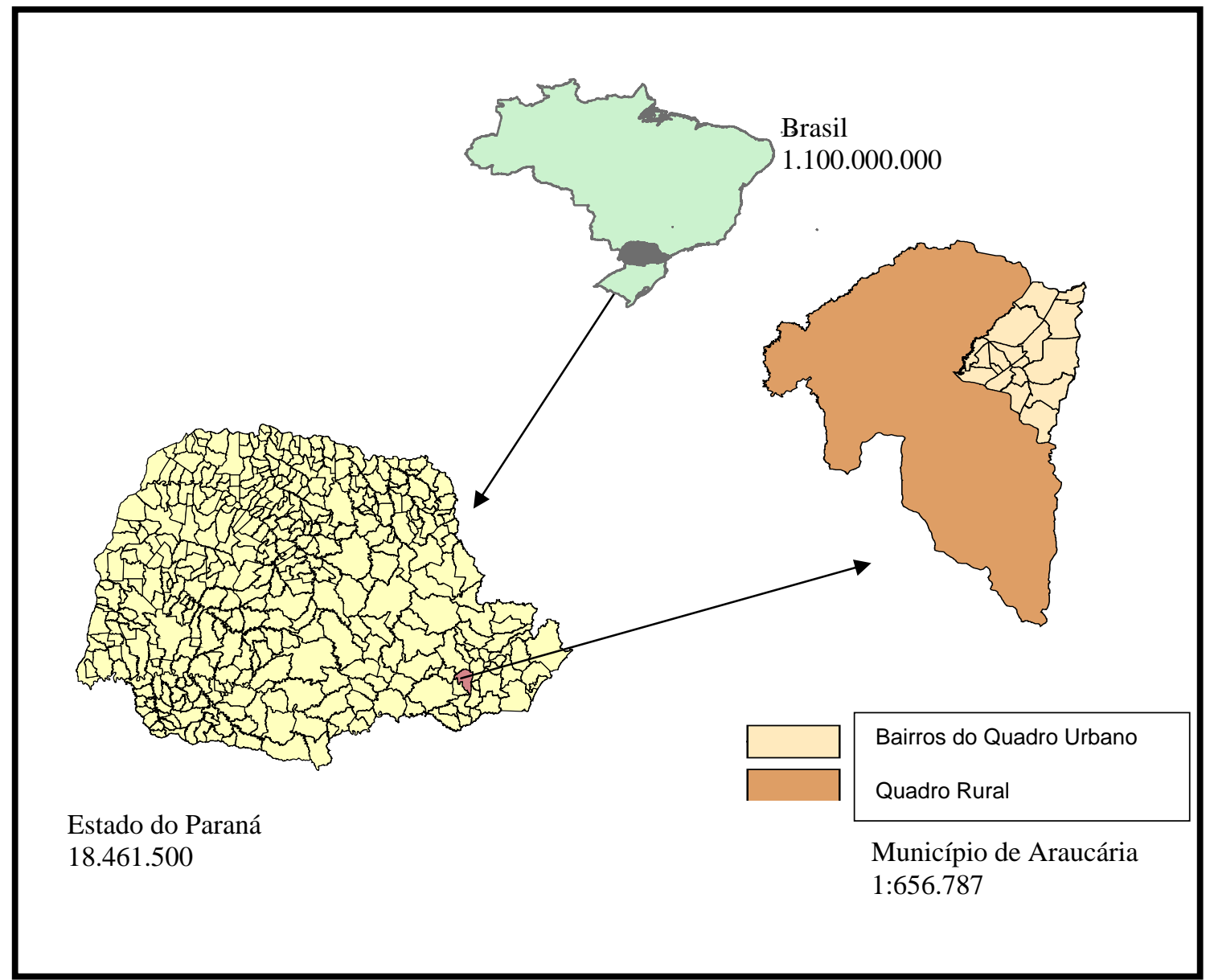

FIGURA 1: LOCALIZAÇÃO DA ÁREA DE ESTUDO - MUNICÍPIO DE ARAUCÁRIA FONTE: SMPL, 2009.

Elaboração: MOURA, N. (2009).

A partir deste momento ocorreu um crescimento bastante acentuado e uma inversão do quadro populacional (Tabela 1), econômico e social do Município, nesta fase a população urbana passou a superar a rural, motivada pela vinda de um contingente populacional de vários pontos do país, fazendo com que a economia que se baseava na agricultura e pecuária passasse a ser predominantemente industrial / urbana (ARAUCÁRIA, 2003).

Turismo \& Sociedade, Curitiba, v. 3, n. 2, p. 220-235, outubro de 2010 
TABELA 1: INVERSÃO DO QUADRO POPULACIONAL URBANO RURAL DE ARAUCÁRIA

\begin{tabular}{llllll}
\hline POPULAÇÃO & $\mathbf{1 9 7 0}$ & $\mathbf{1 9 8 0}$ & $\mathbf{1 9 9 1}$ & $\mathbf{1 9 9 6}$ & $\mathbf{2 0 0 0}$ \\
\hline Urbana & 5.473 & 27.128 & 54.074 & 68.648 & 86.111 \\
Rural & 11.664 & 7.671 & 7.693 & 8.036 & 8.147 \\
Município & 17.177 & 34.799 & 61.797 & 76.684 & 94.258 \\
\hline
\end{tabular}

FONTE: IBGE, 2000.

Organização: MOURA, N. (2009).

De 1970 para 2000 houve um acréscimo populacional de 77.081 indivíduos sendo mais expressivo o seu adensamento no meio urbano do município e um decréscimo acentuado do meio rural. Isso denota que houve uma mudança bastante expressiva da condição de predominância rural em 1970 para urbana nos demais anos assinalados.

\subsection{O PANORAMA DA ATIVIDADE TURÍSTICA NO MUNICÍPIO}

Verifica-se que os direcionamentos no setor turístico do Município de Araucária são em sua grande maioria, atrelados aos segmentos do turismo rural e de negócios, sendo este último mais vinculado à abordagem do presente trabalho, pois:

[...] turismo de negócios, justificado pela sua proximidade com a área industrial de Curitiba e por abrigar um importante complexo industrial. A ocupação média dos meios de hospedagem varia de 30\% a 70\% ao mês, sofrendo variações em função dos eventos realizados nas empresas e indústrias ${ }^{1}$.

Entretanto, o município ainda não dispõe de elementos consolidados para a realização de um turismo industrial. A opção feita pelo poder público do Município foi a de investir de forma mais evidenciada no segmento de turismo rural como forma de impulsionar o pequeno e médio agricultor e a agricultura familiar (ARAUCÁRIA, 2010). Tal investimento tem por objetivo:

1 ARAUCÁRIA. PREFEITURA MUNICIPAL. Turismo em Araucária. Disponível em: <http://www.araucaria.pr.gov.br/index.php?a=turismo.php\&b=turismo>. Acesso em: 15/08/2009.

Turismo \& Sociedade, Curitiba, v. 3, n. 2, p. 220-235, outubro de 2010 
[...] promover o resgate cultural do homem do campo, através das atividades rurais, da gastronomia, das festas tradicionais e do artesanato, possibilitando também um maior contato com a natureza².

Deste modo, a Secretaria Municipal de Cultura e Lazer de Araucária procura promover o entendimento de que:

[...] a identidade de Araucária não se restrinja somente às indústrias e à tecnologia, aliando à sua imagem os diversos elementos presentes na cultura, na história, na área rural, na gastronomia, nos eventos, além de outras características que contribuam para a composição de um cenário muito mais abrangente e turisticamente atrativo ${ }^{3}$.

Com base nestas colocações se pode observar a intenção de não se ater ao foco do industrial, ou ainda, da imagem industrializada que o Município possui. Entretanto, através de conversas informais com a população, realizadas durante o trabalho de execução do presente artigo, pôde-se verificar que Araucária é conhecida justamente por este diferencial. É um município industrializado massivamente e mesmo que possua uma característica rural bastante presente, as indústrias o fazem conhecido no cenário do senso comum.

Neste sentido, se torna pertinente apresentar um esboço do que poderia se transformar em uma possibilidade a mais para o desenvolvimento local: o turismo industrial.

\subsection{A INFRAESTRUTURA}

O urbano traz, imbricado em seu conceito, inúmeras nuances: áreas urbanizadas, altas concentrações populacionais, desenvolvimento industrial acelerado, um estatuto (MOURA, 2009). Além destes aspectos de ordem legal, a autora menciona que também merecem atenção as particularidades culturais atuantes no seio da sociedade urbana, ao passo que estas podem ser analisadas sob diferentes dimensões que se interpenetram. Sendo assim, se pode dizer que o urbano se constitui no ambiente social e culturalmente

2 ARAUCÁRIA. PREFEITURA MUNICIPAL. Turismo em Araucária. Disponível em: <http://www.araucaria.pr.gov.br/index.php?a=turismo.php\&b=turismo>. Acesso em: 15/08/2009. ${ }^{3}$ Idem.

Turismo \& Sociedade, Curitiba, v. 3, n. 2, p. 220-235, outubro de 2010 
modificado com o objetivo de servir de palco à morada humana, atendendo suas necessidades gerais.

Dentre tais necessidades se podem salientar a importância do lazer, bem como as opções de oferta de serviços, instalações e equipamentos para suprir o mesmo. Neste sentido, a infraestrutura necessária para atender uma possível nova demanda turística requer que muitos aspectos sejam devidamente acolhidos nas propostas de planejamento urbano realizadas pelos municípios, a fim de atender os interesses do setor, bem como promovê-los.

O Município de Araucária possui infraestrutura básica bem estruturada que serviu como suporte inicial à implantação do roteiro de turismo rural já existente: “Caminhos de Guajuvira”4 . Tal condição também pode ser considerada como elemento facilitador para uma nova proposta alinhada a um roteiro de base industrial em seu contexto urbano. Além disso, o município conta com serviços de comunicações, dentre eles: jornais, emissoras de rádio e recebe sinais de TV aberta, advindos da capital Curitiba, além de um canal local que transmite as informações citadinas. As opções de transporte coletivo estão conectadas com a capital, embora necessitem de melhoramentos, facilitando o translado. A energia elétrica e a água encanada chegam a todos os bairros, entretanto a rede de esgoto necessita de grandes investimentos por parte do poder público. A rede de hotéis e pousadas é modesta, mas estão previstos grandes investimentos no setor (NASCIMENTO, 2010) ${ }^{5}$.

Todos estes elementos caracterizam Araucária como portadora de um potencial relevante para o turismo industrial, pois agrega elementos básicos já estabelecidos com o parque industrial consolidado em seu território.

\footnotetext{
${ }^{4}$ O Roteiro oferece ao turista a oportunidade de ter contato com a vida no campo e a diversidade cultural das famílias descendentes de imigrantes, principalmente poloneses. São belas paisagens rurais, rios, horto florestal, chácara com produção de flores, artesanato rural e gastronomia, incluindo o tradicional café rural típico polonês, com broa caseira e cuque com farofa doce. O roteiro funciona todos os sábados, onde um ônibus leva os visitantes a todos os pontos do Roteiro de Turismo Rural "Caminhos de Guajuvira". ARAUCÁRIA. PREFEITURA MUNICIPAL. Turismo Rural “Caminhos do Guajuvira”. Disponível em: <http://www.araucaria.pr.gov.br/index.php?a=turismo_rural.php\&b=turismo>. Acesso em: 10/09/2010.

${ }^{5}$ A esse respeito e ainda de acordo com dados divulgados pela Prefeitura Municipal, Araucária possui 6 hotéis correspondendo a 210 apartamentos/quartos e 656 leitos. ARAUCÁRIA. PREFEITURA MUNICIPAL. Visite Hraucária Hospedagem. Disponível em: $<$ http://www.araucaria.pr.gov.br/index.php?a=hoteis.php\&b=turismo>. Acesso em: 10/09/2010.
}

Turismo \& Sociedade, Curitiba, v. 3, n. 2, p. 220-235, outubro de 2010 
Segundo Bahl (2004) todos estes tipos de fatores devem ser levados em conta no momento do planejamento de roteiros turísticos, como é o caso em discussão, pois devem se adequar à intenção do turista em usufruí-los, ou seja, deve levar em conta o público-alvo a que se destinam “oportunizando oferecer um produto passível de consumo e altamente motivador, devendo ser exposto de maneira clara e objetiva” (Idem, p. 32).

Assim, o potencial atrelado à infraestrutura básica presente no município (ainda que deficitária em alguns locais) pode servir como fator positivo para o planejamento deste tipo de oferta, pois, o planejamento eficiente de um destino para o turismo requer estudos que possibilitem "a adequação de estruturas e equipamentos de fundamental importância” para a valorização do mesmo (BAHL, 2004, p. 53). O turismo industrial, atrelado ao já existente roteiro de turismo rural, fariam o diferencial de atratividade do município no panorama do estado. Neste sentido, se julga ser oportuna a inserção de Araucária e seu contexto dentro do setor turístico, ressaltando as possibilidades para o turismo industrial, mas, no entanto, se julga pertinente tecer um relato acerca do parque industrial do referido Município, a fim de situar o seu panorama municipal.

\section{O MUNICÍPIO DE ARAUCÁRIA E O TURISMO INDUSTRIAL}

O segmento do turismo industrial, assim como outras formas de turismo pautadas em roteiros, tem como alicerce a oferta de recursos e serviços básicos e turísticos e a existência de uma demanda de potenciais interessados em consumi-los. Neste sentido, a oferta do produto turístico com o qual se trabalha como ideia no presente artigo se evidencia no cenário estadual a partir de um dos maiores parques industriais do Paraná. Por sua vez, a demanda estaria centrada, então, em dois segmentos: em primeiro, os visitantes que vêm em busca do roteiro rural já existente; e em segundo, os visitantes (negociantes, técnicos e representantes) que vêm para o Município em virtude das industriais nele presentes. Ao mesmo tempo, com a estruturação de um turismo de base industrial poder-se-ia buscar outro tipo de turistas que viriam para Araucária para participar basicamente de tal cenário. Neste sentido, segue uma descrição de seu panorama de desenvolvimento industrial, pois é em seu 
contexto que se podem elencar as possibilidades de organização de um roteiro de turismo industrial ou da complementação de opção ao já existente roteiro de turismo rural.

\subsection{INDÚSTRIAS MUNICIPAIS}

No âmbito do Município de Araucária, áreas industriais, ou centros industriais, são empreendimentos criados pela Prefeitura Municipal para coordenar e gerir a implantação das indústrias na sua área, segundo a Companhia de Desenvolvimento de Araucária (CODAR, 2008) ${ }^{6}$. A função destes centros é “compartilhar variáveis como mão-de-obra, matéria-prima, infraestrutura urbana e social, ordenando o desenvolvimento industrial com grandes vantagens para os empresários” (CODAR, 2008). Consta ainda de acordo com dados da Prefeitura Municipal (ARAUCÁRIA, 1999) que o Centro Industrial de Araucária (CIAR) foi “cuidadosamente planejado para receber indústrias. A preocupação com os ventos dominantes, preservação dos fundos de vale e proteção dos mananciais de água nortearam a localização das áreas industriais".

O Parque industrial do município conta com aproximadamente 3.000 unidades empresariais atuantes, empregando um total de 40.100 pessoas (IBGE, 2008). As indústrias do referido parque industrial, são do complexo petroquímico e de papel e celulose, metalúrgicas e pequenas indústrias variadas, além de possuir um importante polo agroindustrial e de multinacionais diversificado.

Estes fatores poderiam se tornar uma considerável oferta turística, que atenderia às demandas mencionadas anteriormente. Assim sendo, se torna pertinente discutir acerca do turismo industrial que se poderia desenvolver no Município.

\subsection{TURISMO INDUSTRIAL EM ARAUCÁRIA: UMA POSSIBILIDADE? UM COMPLEMENTO?}

A admiração pelas paisagens faz com que muitos procurem o turismo como forma de sanar a curiosidade inerente ao ser humano. Conhecer, vislumbrar, desfrutar

\footnotetext{
${ }^{6}$ Disponível em: <www.codarpr.com.br>. Acesso em: 05/11/2008.
}

Turismo \& Sociedade, Curitiba, v. 3, n. 2, p. 220-235, outubro de 2010 
de novos ambientes são necessidades presentes nas sociedades. Neste sentido, se pode traçar um paralelo entre as paisagens naturais e as construídas pelo homem, que do mesmo modo que as primeiras, também chamam a atenção de muitos olhares curiosos. Entre as últimas, encontram-se as paisagens industriais, com sua arquitetura e organização diferenciadas e funcionais para atender as necessidades do objetivo para o qual foram configuradas.

Para Capel (1995) o turismo industrial pode ser entendido como

[...] una rama nueva de la actividad turística que está teniendo un desarrollo espectacular en los últimos años y que ha conducido a la aparición de una nueva rama de la geografía del turismo, denominada precisamente como turismo industrial. Ese turismo se traduce hoy no solo en visitas a las instalaciones industriales ya en desuso sino también a los complejos industriales actuales que se encuentran en funcionamiento (CAPEL, 1995, p. 14).

O mesmo autor salienta também que o turismo industrial pode estar ligado à complementação de outras rotas já existentes, entrando como uma possibilidade a mais para a visitação (CAPEL, 1995).

O turismo industrial tem sido apontado em alguns municípios brasileiros como fonte de aproveitamento de um potencial a ser explorado. Este é o caso dos municípios de Maringá ${ }^{7}$, no norte paranaense, e de Joinville, Blumenau, Pomerode e São Bento do Sul, no Estado de Santa Catarina ${ }^{8}$. Estes municípios estabeleceram diretrizes para o aproveitamento deste potencial, com vistas a impulsionar o setor turístico e criar novas oportunidades de investimentos e geração de empregos e renda. O território ganha neste âmbito, conotações diferenciadas, mas sem alterar sua finalidade.

\footnotetext{
${ }^{7}$ [...] Neste contexto, surgiu o projeto do Maringá Convention \& Visitors Bureau, denominado "turismo industrial”, atividade que vem se aprimorando de uma forma extraordinária nos últimos anos em várias destinações estrangeiras, como um novo segmento da atividade turística, valorizando os aspectos locais da cidade. COUTINHO, D. Um novo segmento do turismo em Maringá. Disponível em: $<$ http://www.maringacvb.com.br/artigosVer.php?artigo_id=463\&id=2>. Acesso em: 29/09/2010.

${ }^{8}$ Em Joinville participam as empresas: CRW Plásticos, Datasul, Logocenter, Perini Business Park, Arroz Vila Nova, Chocopp, Laboratório Catarinense, Tigre. Em São Bento do Sul: Móveis Rudnick, Oxford, Condor. Na pequena Pomerode: Pomerode Laticínios, Kyly Indústria Têxtil, Behling Estilo Fazenda, Cativa Têxtil Indústria, Porcelana Schmidt e em Blumenau: Cervejaria Eisenbahn, Glass Park, Fornos Jung, Sulfabril, Hering, Cristais Hering, Altenburg, Momento Engenharia e Bernauer. Vide em: $<$ http://www.belasantacatarina.com.br/noticias.asp?id=1778>. Acesso em: 29/09/2010.
}

Turismo \& Sociedade, Curitiba, v. 3, n. 2, p. 220-235, outubro de 2010 
Neste sentido, torna-se pertinente afirmar que o território municipal pode se constituir de vários outros tipos de territórios, incluindo aqueles organizados pelo homem, como seria o caso dos territórios turísticos.

Ressaltando as diferenças entre território e espaço, toma-se como base o conceito de território em que se funda Raffestin (1980) segundo o qual se verifica que território e espaço não podem ser considerados como terminologias equivalentes. Ambos os conceitos possuem suas especificidades. O espaço, em seu âmbito, é anterior ao território, pois este necessita de que alguém o possua, ou seja, ele é resultado "de uma ação conduzida por um ator sintagmático” (FRAGA, 2007). Neste sentido, é pertinente observar que a apropriação do espaço por este ator ou atores é que faz com que o mesmo se constitua também em um território.

Assim, quando um turista entra em contato com o ambiente visitado estabelece algum tipo de vínculo com o território, fato que pode o fazer querer voltar ou não àquele local. Tal fato irá depender da atratividade do local em si, ou como no caso em estudo, da participação em um roteiro local baseado em atrativos industriais, que poderia estar inserido em complementação à programação de uma viagem. Segundo Bahl (2004, p. 31) "mesmo que os roteiros dependam da execução ou participação em uma viagem, também podem aglutinar temáticas e objetivos que estimulem as pessoas a viajar, complementando-os”.

A característica iminentemente industrial em que se encontra inserido o Município de Araucária, torna-se um fato marcante na criação de uma imagem de seu território dentro e fora de seus limites, assim o planejamento de um roteiro turístico bem idealizado daria conta de reunir os "diversos elementos que apresentem os mais diversos aspectos de uma região ou localidade” (BAHL, 2004, p. 52-53) no caso vinculando-se aos aspectos industriais do município. Neste sentido, conforme mencionando anteriormente, o turismo industrial também poderia ser visto como um complemento ao roteiro de turismo rural já implementado. Excluindo-se, assim, a substituição de uma oferta pela outra e colocando-se a alternativa da complementação como forma de organização e enriquecimento da oferta turística no município. Deste modo, a criatividade no momento do planejamento do roteiro poderia torná-lo um grande atrativo, que, ainda segundo Bahl (2004) incrementa o aspecto econômico que a atividade gera, desde que bem planejada.

Turismo \& Sociedade, Curitiba, v. 3, n. 2, p. 220-235, outubro de 2010 
Deste modo, ocorreria à criação de uma nova proposta de produto para complementação da atual oferta turística, ou, em termos geográficos, ocorreria a conformação de uma nova visão da paisagem já existente, uma paisagem configurada $a$ priori por um determinado uso, mas que com o reinventar das organizações que permeia a sociedade, passaria a ganhar novos contornos. Neste sentido, Luchiari (1998) salienta que as paisagens turísticas não existem a priori como um dado da natureza, diferindo assim dos demais tipos de paisagens naturais. Deste modo, o turismo seria incorporado à paisagem sem alterá-la. Segundo Cruz (2002):

[...] as paisagens turísticas não são caracterizadas por um sistema de objetos que lhe seja particular, específico. As paisagens turísticas derivam da valorização cultural de determinados aspectos das paisagens, de modo geral, e, nesse sentido, toda paisagem pode ser turística (CRUZ, 2002, p. 16-17).

Assim sendo, as paisagens industrializadas presentes no Município de Araucária, poderiam muito bem ser adequadas e organizadas para atender a uma demanda turística interessada em conhecer e visitar instalações industriais. Para Knafou (1996) o processo de transformação e adequação de um território em um território turístico requer a readequação do mesmo à funcionalidade que lhe queiram investir, ou seja, ele deverá inserir em sua existência a especialização necessária ao novo uso.

Deste modo, o território turístico pode ser caracterizado como o espaço em que foi incorporado um uso pelo turismo, isto é, aquele que foi de algum modo funcionalizado para o turismo. Assim, ao se instaurar um apêndice à oferta turística no Município de Araucária expresso pelo turismo industrial, conformar-se-ia um território turístico distinto dentro do mesmo, pois ele passaria a existir com uma funcionalidade diferente daquela para a qual foi inicialmente organizado, entretanto, não será por este motivo que a primeira funcionalidade deixará de existir, elas coexistirão, porém, como territórios entendidos de modo diferenciado.

Neste sentido, o mesmo território abrigaria diferentes visões a seu respeito. Ou ainda, como coloca Haesbaert (2009) o território abrigará diferenciadas territorialidades advindas daqueles que se fazem presentes em seus domínios. Nestes parâmetros, a territorialidade envolve o controle da área, mesmo que temporário. As informações se entrecruzam e confrontam, dando origem às territorialidades presentes e inerentes ao território, neste caso, o território turístico. Quando estão em contato com os lugares turísticos os indivíduos interagem entre si, criando círculos de convivência no espaço Turismo \& Sociedade, Curitiba, v. 3, n. 2, p. 220-235, outubro de 2010 
habitado, onde cada indivíduo ou grupo vai exercer o controle sobre o território, ou seja, sua territorialidade. Para Sack (1986) a territorialidade envolve o controle de uma área:

Territoriality for humans is a powerful geographic strategy to control people and things by controlling area. Political territories and private ownership of land may be its most familiar forms but territoriality occurs to varying degrees en numerous social contexts (SACK, 1986, p. 5)

Assim, os territórios turísticos são produzidos pelos turistas no âmbito de suas práticas e podem ser tomados pelos planejadores como forma de incentivar e desenvolver a atividade no mercado (KNAFOU, 1996). Uma vez estando nas áreas visitadas, o turista acaba por exercer sua influência na mesma. Deste modo, é ressaltada a importância do turista no entendimento das práticas territoriais (CRUZ, 2002), ou seja, sem turista no lugar, sem o reconhecimento que este projeta sobre tal lugar, não há razão para que o mesmo continue a existir como turístico.

No caso de Araucária há que se assinalar que existe circulação de visitantes que em princípio não estão alinhados ao turismo de lazer ou recreativo, pois em sua maioria desenvolvem atividades de visitas técnicas às indústrias ou para a realização de negócios. Também se identifica a presença de muitos excursionistas que percorrem o itinerário turístico do "Caminhos do Guajuvira” e nele também desenvolvem atividades alinhadas ao turismo rural.

A ideia de se propor uma nova modalidade de opções turísticas baseadas no aparato industrial do município poderia ser uma forma de se estabelecer uma complementação das programações já existentes. Além disso, seria uma oportunidade para estabelecer programações mais direcionadas às indústrias e de circulação na já existente estrutura urbana assim adaptada em seu território.

\section{CONCLUSÃO}

A partir do enfoque abordado neste trabalho identificou-se o grande potencial de Araucária para o desenvolvimento de atividades vinculadas ao desenvolvimento de produtos turísticos alinhados ao segmento de turismo industrial. Isso, tanto na elaboração de roteiros de visitação às instalações industriais quanto na preparação de 
tais tipos de instalações como opção para visitas coletivas ou isoladas e ainda na complementação de programações já existentes.

Nesta conjuntura, Araucária se enquadraria como um possível território para o turismo industrial, pois, assim é conhecida em nível de senso comum, ideia corroborada por seu estruturado parque industrial, que abriga inúmeros meios de produção, que por sua vez, ofertam opção de renda, trabalho e inúmeros recursos necessários à manutenção da vida moderna. Visitar e saber como funciona a produção de tais recursos poderia se tornar um atrativo instigante.

Além de tais particularidades, a prática do turismo nestes moldes passaria por uma das suas características fundamentais que é o fato deste se constituir numa prática social que projeta o indivíduo no âmbito do conhecimento sobre os fatores vitais da sociedade, ou seja, o saber sobre os elementos essenciais à vida moderna, além de ser opção de lazer e entretenimento.

Neste sentido, quando o indivíduo se encontra no lugar a ser visitado, ele instala ali uma parte de suas vivências, de seus hábitos e costumes que, por sua vez, se confrontam com os daqueles que são sedentários de tal lugar. Assim, uma nova territorialidade se inaugura, podendo ser fixada por períodos de tempo relativamente curtos, mas que podem gerar algum tipo de influência, seja para os que o visitarem, seja para os que são moradores permanentes.

Assim, o território turístico é de certa forma, apropriado por indivíduos que ali se encontram e atuam por períodos de tempo determinados. Deve-se, no entanto, salientar que as atuações dos grupos de pessoas que se incorporam nestes territórios não têm todos os mesmos interesses e nem as atuações se dão na mesma conjuntura. Portanto, cabe ressaltar que existem nestes espaços, então, diferentes tipos de territórios em um mesmo território, ou seja, o território do turismo se dá mediante a atuação de sujeitos que o compreendem como tal. Moradores e visitantes possuem diferenciadas visões sobre o território no qual se encontram, mas o cerne do entendimento passa pelo mesmo ponto de vista: aquele território ser alvo do fluxo de turistas.

Neste sentido, tal tipo de produto poderia ser tanto uma possibilidade como um complemento à oferta turística já existente. Uma possibilidade, pois, aumentaria as opções de atrativos já existentes com um aparato que poucas cidades do país possuem. Um complemento, pois ampliaria o sentido do turismo municipal, uma vez que o 
Município ganha maior destaque no setor industrial, em nível de senso comum, do que no de âmbito rural.

Com esta visão inicial se pretendeu colocar a possibilidade da inserção do Município de Araucária no cenário dos municípios que investem no turismo industrial como fonte de incremento ao setor turístico. Desta forma, alargando seus horizontes e propondo novos atrativos. Por sua vez, o enquadramento do Município enquanto opção de lazer e entretenimento diversificado se ampliaria e se caracterizaria como um território com diferenciadas possibilidades, um território para o turismo industrial.

\section{REFERÊNCIAS}

ARAUCÁRIA, PREFEITURA MUNICIPAL. Da madeira ao aço: a industrialização de Araucária. Prefeitura de Araucária, 1999.

Perfil Municipal. Araucária, 2003.

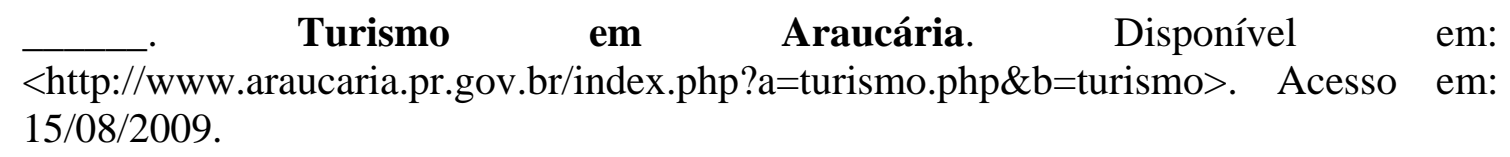

Atrativos turísticos. Disponível em:

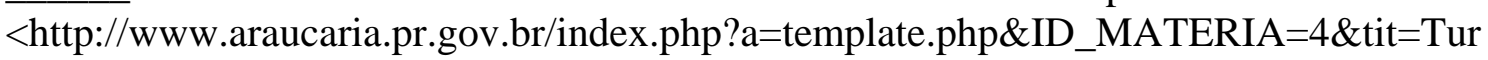
ismo>. Acesso em: jul./2010.

. Turismo Rural “Caminhos do Guajuvira”. Disponível em: $<$ http://www.araucaria.pr.gov.br/index.php?a=turismo_rural.php\&b=turismo>. Acesso em: 10/09/2010.

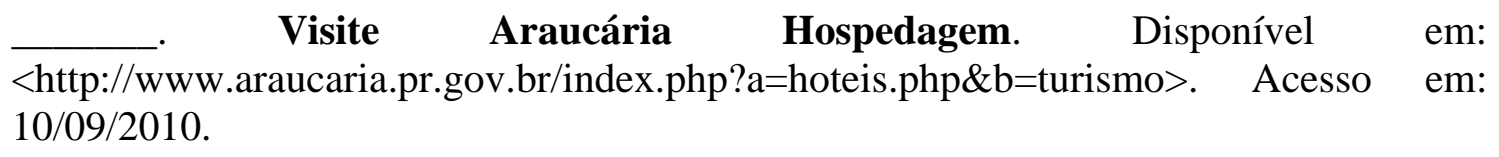
. Secretaria Municipal de Planejamento Urbano: SMPL, 2009.

BAHL, M. Viagens e roteiros turísticos. Curitiba: Protexto, 2004.

BELA SANTA CATARINA. Disponível em: <http://www.belasantacatarina.com.br/noticias.asp?id=1778>. Acesso em: 29/09/2010.

CAPEL, H. El turismo industrial y el patrimonio histórico de la electricidad. Sevilla: Scripta Vetera, 1995. p. 170-195. 
CODAR, Companhia de Desenvolvimento de Araucária. Disponível em: $<$ www.araucaria.pr.gov.br>. Acesso em: ago./2009.

COUTINHO, D. Um novo segmento do turismo em Maringá. Disponível em: $<$ http://www.maringacvb.com.br/artigosVer.php?artigo_id=463\&id=2>. Acesso em: 29/09/2010.

CRUZ, R. de C. A. Políticas de turismo e território. São Paulo: Contexto, 2002.

FIRKOWSKI. O. L. C. F. A nova territorialidade da indústria e o aglomerado metropolitano de Curitiba. Tese (Doutorado em Geografia). Universidade de São Paulo, São Paulo, 2001.

FRAGA, N. C. Território, região, poder e rede: olhares e possibilidades conceituais de aproximação. Relações Internacionais no Mundo Atual, Curitiba, a.VII, n. 7, p. 9-32, 2007.

HAESBAERT, R. O mito da desterritorialização. Do fim dos territórios à multiterritorilidade. Rio de Janeiro: Bertrand Brasil, 2009.

IBGE - INSTITUTO BRASILEIRO DE GEOGRAFIA E ESTATÍSTICA. Censos Demográficos, 2008. Disponível em: <www.ibge.gov.br>. Acesso em: ago./2010.

KNAFOU, R. Turismo e território. Por uma abordagem científica do turismo. In: RODRIGUES, A. B. (Org.) Turismo e Geografia - reflexões teóricas e enfoques regionais. São Paulo: Hucitec, 1996.

LUCHIARI, M. T. D. P. Urbanização turística - um novo nexo entre o lugar e o mundo. In: LIMA, L. C. (Org.) Da cidade ao campo: a diversidade do saber fazer turístico. Fortaleza: UECE, 1998, p. 15-29.

MOURA, N. Araucária / PR: planejamento urbano e representações sociais. Dissertação (Mestrado em Geografia). Universidade Federal do Paraná, Curitiba, 2009.

NASCIMENTO, A. C. Obra na REPAR inicia novo ciclo em Araucária. In: GAZETA DO POVO, JORNAL. Disponível em: $<$ http://www.gazetadopovo.com.br/economia/conteudo.phtml?tl=1\&id=973629\&tit=Ob ra-na-Repar-inicia-novo-ciclo-em-Araucaria>. Acesso: jun./2010.

RAFFESTIN, C. Por uma geografia do poder. São Paulo: Ática, 1980.

SACK, R. D. human territoriality. Its theory and history. Cambridge: Cambridge University Press, 1986.

Recebido em: 24/08/2010.

Aprovado em: 24/09/2010.

Turismo \& Sociedade, Curitiba, v. 3, n. 2, p. 220-235, outubro de 2010 